ISSN: 2238-8052

\title{
QUEM TEM O DIREITO DE MORAR? DESENVOLVIMENTO URBANO E INTERESSES DE CLASSE NA CIDADE DE ARAPIRACA-AL
}

\author{
WHO HAS THE RIGHT TO DWELL? URBAN DEVELOPMENT AND CLASS INTERESTS IN THE \\ ARAPIRACA-AL CITY
}

Rodolfo José Oliveira LIMA ${ }^{1}$

Palavras-chave: Arapiraca, Urbanização, Espaço, Habitação, Interesses de classe.

\section{R E S U M O}

Este trabalho tem por objetivo discutir o fenômeno de urbanização pelo qual a cidade de Arapiraca-AL vem passando a partir de uma área em especial: as imediações do açude do Departamento Nacional de Obras Contra as Secas (DNOCS), atualmente rebatizado de "Lago da Perucaba". Nessa área, famílias tradicionais de pescadores estão sendo ameaçadas de expulsão de seu local de moradia e sustento para dar lugar a um hotel de luxo que faz parte do empreendimento "Perucaba Bairro Planejado". Pretende-se mostrar que a urbanização da área está inserida em toda uma lógica de desenvolvimento capitalista que se apropria (e expropria) do espaço como forma de garantir a sua reprodução/acumulação. Para orientar esse debate, será feita uma discussão sobre o que é o espaço e a habitação no sistema capitalista, como pressuposto necessário para a compreensão da realidade.

\section{A B S T R A C T}

This work aims to discuss the urban phenomenon by which the Arapiraca-AL city has been passing in a special area: the surroundings of Departamento Nacional de Obras Contra as Secas (DNOCS) weir, currently renamed "Lago da Perucaba". In this area, ancients families of fishermen are being threatened of expulsion from their place of dwelling and livelihood to make way for a luxury hotel that is part of the "Perucaba Bairro Planejado" project. It is intended to evidence that the urbanization of the area is insert in a capitalist development logic that appropriates (or expropriates) the space as a way to guarantee its reproduction / accumulation. To guide this debate, there will be a discussion about what is space and habitation in the capitalist system, as a necessary presupposition for understanding reality.

\section{INTRODUÇÃO: UM PANORAMA DA CIDADE}

Arapiraca localiza-se no centro do Estado de Alagoas, é uma cidade de médio porte com uma estimativa populacional de aproximadamente 230 mil habitantes em 2018 (IBGE, 2018); possui um território de $345,655 \mathrm{~km}^{2}$ fazendo parte da mesorregião do Agreste. É uma das cidades que mais cresce no Estado, sendo o segundo maior município; já foi conhecida como "A capital brasileira do fumo" por

\footnotetext{
1 Possui Graduação em História pela Universidade Estadual de Alagoas - UNEAL - e Especialização em Metodologia do Ensino de História pela Faculdade de Ensino Regional Alternativa - FERA. Mestrando do Programa de Pós-Graduação em História da Universidade Federal de Alagoas - UFAL. E-mail: rjoliveira.lima@yahoo.com.br.
} 
possuir na década de 1970 a maior área de plantio de tabaco do país, chegando a ser responsável, no final de 1980, por 90\% da produção nacional de fumo em corda (NARDI, 2010). Contudo, por sua posição estratégica no centro do Estado, hoje o setor terciário é de longe o que mais se destaca, sendo mais de três vezes maior que a renda bruta da agropecuária e indústria juntas, com o total anual de R\$ 2.126.985 (mil reais), contra $\mathrm{R} \$ 678.832$ (mil reais) dos outros dois setores somados (IBGE, 2016). Esse destaque do comércio é explicado por Firmino (2016, p. 134):

\begin{abstract}
Arapiraca apresentava facilidade no que se refere a ligação entre litoral e sertão, o que contribuiu significativamente na atuação e no desempenho do seu setor econômico, já que servia também como lugar de troca de produtos advindos tanto do litoral rumando ao sertão, como do sertão ao litoral. Isto foi facilitado com a construção de rodovias por volta da década de 1950.
\end{abstract}

Cidade e campo, separados dentro da divisão social do trabalho no capitalismo, encontram um elo nas feiras livres onde a troca entre os gêneros produzidos em cada uma das esferas acontece de forma direta (LIMA, 2012). Deste modo, a história da cidade sempre foi marcada pela presença desse tipo de comércio, existindo atualmente, conforme o cadastramento feito pela Prefeitura, 10 feiraslivres espalhadas pelos diversos bairros da cidade (ARAPIRACA, s.n.t.). De acordo com Guedes (1999), a criação da feira mais tradicional da cidade que ocorre todas as segundas-feiras, remota a 1884 como forma de intercambiar os produtos rurais do então povoado de Arapiraca, pertencente à Limoeiro de Anadia, seu exponencial crescimento levou-a a superar o município, sendo emancipada em 1924. Essa foi uma típica relação que encontramos no desenvolvimento das cidades no Agreste nordestino onde predominou o minifúndio. As propriedades são bastante divididas e as condições de vida da população são humildes, tendo basicamente como única forma de transporte a tração animal; isso permite "maior divisão do dinheiro: diminui o número de ricos e de pobres, aumentando o de remediadores. Por isso, feiras [locais, mesmo que pequenas] apesar da pequena população do aglomerado, são muito mais importantes do que as de cidades grandes da zona da Mata" (ANDRADE, 2011, p.170).

É sob um ritmo acelerado que Arapiraca cresce, sendo o principal centro comercial da região, onde nota-se que o avanço da "modernização" tem modificado claramente suas feições. As próprias feiras de rua, comércio típico de pequenos mercadores, sofreram mudanças significativas em suas localizações, formas e periodicidades à medida que o varejo de médio e grande porte chegou à cidade, sobrepondo seus interesses na organização espacial da mesma. Mas não só. As cidades médias possuíram um papel de destaque no panorama de urbanização do Brasil a partir da segunda metade do século XX, caracterizado pela concentração da população brasileira nas grandes metrópoles e nos centros de médio porte, sendo estes últimos responsáveis por mais da metade da população do país (SANTOS, 1993). Tal caráter trouxe a estas cidades uma realidade partilhada pelos grandes aglomerados urbanos: a exclusão social. Destarte, em Arapiraca vamos encontrar diversos casos de gentrificação, expulsão e transferências de famílias de áreas centrais para a periferia, dando lugar a empreendimentos imobiliários, assim como o aumento do perímetro urbano da cidade engolindo 
comunidades rurais de modo a possibilitar a construção de loteamentos pelo programa "Minha Casa Minha Vida" do Governo Federal, já que o mesmo destina-se apenas a localidades na zona urbana.

Dentre esses casos, um em especial nos chama a atenção para essa pesquisa, o processo de urbanização do Açude do Departamento Nacional de Obras Contra as Secas (DNOCS), atualmente rebatizado de "Lago da Perucaba". Nessa área, famílias tradicionais de pescadores estão sendo ameaçadas de expulsão de seu local de moradia e sustento para dar lugar a um hotel de luxo que faz parte do empreendimento "Perucaba Bairro Planejado". Pretende-se mostrar que a urbanização local está inserida em toda uma lógica de desenvolvimento capitalista que se apropria (ou expropria) do espaço como forma de garantir a sua reprodução/acumulação. Para fundamentar esse debate, entender o que é o espaço e a habitação (já que estamos lidando diretamente com a transformação do primeiro e buscando entender como a necessidade fundamental humana de morar é marcada pelo capitalismo), é um pressuposto necessário para a compreensão da realidade. Entender a cidade a partir da conjuntura (social, econômica e política) em que está inserida foi algo impossível de ser menosprezado, mesmo em se tratando de uma cidade do interior.

\section{ESPAÇO E HABITAÇÃO NO CAPITALISMO}

Milton Santos (2014) nos traz uma concepção já bastante difundida quando falamos em seu pensamento sobre o espaço. 0 mesmo autor o define como um híbrido formado por "sistema de objetos" e "sistemas de ações" que interagem entre si mutualmente e, também, contraditoriamente. Se é possível explicar sinteticamente o que são esses sistemas de objetos e de ações, teríamos os primeiros como as forças produtivas e os segundos como as relações materiais de produção. 0 espaço é formado por sucessões e coexistências de seus objetos e atores, não é algo isolado, mas onde o todo e suas partes se realizam, assim como a história, a geografia, os objetos, os símbolos, etc. Não deve ser visto como a soma dos lugares, peças ou produtos, e sim como uma totalidade. 0 espaço permeia tudo, inclusive as relações sociais, o Estado e as superestruturas no geral.

Esse pressuposto carrega uma série de implicações para a forma como o pesquisador enxerga a realidade. Significa ter o espaço como uma categoria ${ }^{2}$ fundamental para a compreensão do mundo, sendo indissociável do tempo, uma vez que, como expõe Lefebvre: "toda a realidade dada no espaço se expõe e se explica por uma gênese no tempo. Mas uma atividade que se desenvolve no tempo (histórico) engendra (produz) um espaço e somente num espaço assume uma "realidade" prática, uma existência concreta (LEFEBVRE, 2006, p. 167, grifos do autor). 0 espaço se introduz no conceito de produção, o invade, isto é, ele mesmo se torna o conteúdo no processo social de produção, sendo deste

${ }^{2}$ As categorias, conforme Netto (2011), são determinações reais (ontológicas) historicamente determinadas de uma sociedade que exprimem seu modo de ser, com as quais o pesquisador lida reproduzindo-as intelectualmente, pertencendo, assim, também ao plano ideal. 
modo uma relação dialética.

A problemática que percorre o espaço decorre do crescimento das forças produtivas, com elas, advém as "ideologias" (no sentido restrito de falsa concepção da realidade); para Lefebvre (2006) é preciso destruir essas ideologias da espacialidade que a mascaram. 0 caminho para isso não seria a fragmentação, ou seja, entender o espaço a partir de subdivisões: o espaço do lazer, do trabalho, etc., mas sempre entendê-lo como uma totalidade. Isto não quer dizer que o autor ignore que existem vários espaços sociais, mas é enfático quanto a sua ligação com o todo. 0 espaço representa a morfologia social, portanto é algo que pode ser depreendido, mesmo nas suas representações abstratas. A separação entre o "espaço vivido", campo da geografia, do urbanismo, da sociologia, etc., do "espaço mental", campo da matemática, da filosofia, é algo que mutila o entendimento da realidade. Isso advém da separação entre teoria e prática, o conceito não pode se separar do vivido.

Pode parecer confuso entender o espaço da abstração como integrado ao mesmo espaço real (material), a princípio acha-se que são coisas diferentes, mas na concepção que estamos expondo, o espaço é o encontro, a reunião de tudo que existe: objetos, natureza, símbolos, conflitos sociais:

\begin{abstract}
A forma do espaço social é o encontro, a reunião, a simultaneidade. 0 que se reúne? 0 que é reunido? Tudo o que há no espaço, tudo o que é produzido, seja pela natureza, seja pela sociedade, - seja por sua cooperação, seja por seus conflitos. Tudo: seres vivos, coisas, objetos, obras, signos e símbolos (LEFEBVRE, 2006, p. 149).
\end{abstract}

Desse debate podemos concluir que o espaço não é imutável, mas também um produto no sentido dialético que foi exposto. Assim, a partir de que pressupostos poderíamos entendê-lo na contemporaneidade? Se espaço não pode ser entendido fora do tempo, qual o tempo predominante no capitalismo? Vamos buscar novamente em Milton Santos $(2013,2014)$ referências para nos ajudar nesses exames.

Como o autor explica, o Mundo cada vez mais se "mundializa", mas os indivíduos são cada vez mais fragmentados, o meio se dinamiza e se torna algo difícil de definir. Existe um tempo universal, mas não uma temporalidade universal (SANTOS, 2013), a cidade é um exemplo disso, quanto maior, mais numerosos são os vetores existentes, assim, temos várias temporalidades que permeiam o espaço. Se podemos sintetizar, teríamos as temporalidades "hegemônicas" que são relativas a economia, a racionalidade, cultura e sociedade e as "hegemonizadas" por essas primeiras. Há uma constante necessidade de atualização posto como um imperativo por essas forças hegemonizadoras sobre as hegemonizadas; podemos claramente ver essa ação no plano individual quando um sujeito se vê forçado a aprender uma nova tecnologia para conseguir se integrar à sociedade. Essas forças hegemônicas agem sobre o espaço, ou sobre os vários espaços, desse modo, também há espaços hegemonizadores e hegemonizados (SANTOS, 2013).

Dessa última afirmação temos a ação do que o autor chama de "horizontalidades" e "verticalidades". As primeiras referem-se ao substrato da vida material de um determinado meio, o 
conjunto das relações entre os indivíduos, instituições etc., diretamente ligados aquela espacialidade, onde também se geram políticas próprias e relações solidárias. As verticalidades (diretamente ligadas ao poder econômico) são relações impostas a partir de fora pelas forças dominantes que trazem sua interferência ao local, são um vetor perturbador, pois implicam a mudança, é estranha aos habitantes locais. 0 mundo hoje é formado por ambas.

A formulação do conceito de "meio técnico-científico-informacional" por Santos (2014) é outro conceito que nos vem a ser bem útil. Dele depreendemos que o espaço é indissociável das técnicas, isto é, das formas de interação entre o homem e a natureza. Por meio da técnica, o historiador pode entender o espaço como um fenômeno histórico (o tempo do processo de trabalho humano). Técnica não se separa da ciência (isto é, a natureza de sua concepção) e possui uma finalidade, um sentido (que é informação). É nessa gama de fatores que o sistema espacial se modifica, se torna mais ou menos denso a depender do grau de ligação com o mundo da produção.

O meio técnico-científico-informacional de hoje é uma sucessão do "meio-técnico" que representou a mecanização da vida, maior símbolo do domínio do homem sobre a natureza - este, por sua vez, sucedeu o "meio natural", a forma de ligação primária do homem com a natureza principalmente a partir da revolução industrial, contudo, ainda sem um contexto interligado, disperso geograficamente. É após a Segunda Guerra Mundial (que marca a união entre técnica e ciência) que temos sua predominância, mas seu auge se dá a partir da década de 1970. A informação representa a unificação global desse meio, isto é, a globalização, subordinada à lógica capitalista.

As cidades contemporâneas são erigidas em torno do meio técnico-científico-informacional. Nesse processo, elas se tornam mais excludentes: "Na cidade, as formas novas, criadas para responder as necessidades renovadas, tornam-se mais exclusivas, mais rígidas material e funcionalmente, tanto do ponto de vista de sua construção quanto de sua localização" (SANTOS, 2013, p. 70). 0 meio técnicocientífico-informacional, antes monopólio dos centros urbanos, agora também abrange o campo. A tecnologia possibilitou a redução do espaço destinado a produção, permitindo a ampliação do meio reservado a circulação e ao consumo:

\footnotetext{
Restringe-se o espaço reservado ao processo direto da produção, enquanto se alarga o espaço das outras instâncias da produção, circulação, distribuição e consumo. Essa redução da área necessária à produção das mesmas quantidades havia sido prevista por Marx, que a esse fenômeno chamou de "redução de arena" (SANTOS, 2014, p. 240, grifo do autor).
}

Já o processo que gera a ampliação do intercâmbio que se dá em espaços mais vastos devido a vantagem de se produzir nos mesmos é o que Marx chama de "ampliação de arena".

A produção capitalista do espaço é algo estudado por Harvey (2005) na obra de mesmo nome, tendo por base uma leitura crítica dos volumes de 0 capital de Marx, também valendo-se da análise das heranças hegelianas e da percepção de outros filósofos. Como o autor expõe, quanto maior a intensificação da atividade social, dos mercados e das pessoas, mais importante é a expansão 
geográfica para sustentar a acumulação do capital. As tendências do capitalismo, a forma como se expande, cria demandas, como constrói paisagens físicas só para depois destruí-las, etc., é exposto pelo autor de forma objetiva.

O capitalismo existe em prol da circulação e cria as condições para tal: "Isso se traduz na ideologia do crescimento ('o crescimento é bom') independentemente das consequências ambiental, humana ou geopolítica" (HARVEY, 2005. P. 130, grifo do autor). A primeira barreira para o acontecimento da circulação é justamente a barreira espacial. 0 capitalismo busca constantemente anular o espaço pelo tempo, isso significa incrementar a mobilidade (e o Estado é o principal garantidor dessa tendência). Isso origina a ótica na qual o Espaço perdeu a importância dentro da dinâmica atual do capitalismo, alguns chegaram até em falar no "fim do espaço", como nos explica Cesar Santos (2015), mas isso é um erro, pois ao contrário o papel do espaço é reforçado, mas sob outra dinâmica, maior e mais complexa.

A tendência do capital à superacumulação que inevitavelmente desemboca nas crises merece uma preocupação especial de Harvey ao abordar a geopolítica do capitalismo. Historicamente esse sistema utilizou-se da expansão geográfica para "resolver" os problemas de suas crises cíclicas, economistas burgueses até expunham tal saída como a solução para essa problemática do capital, mas para Harvey isso é falso. A expansão/reestruturação geográfica do capitalismo é algo que apenas posterga as crises, contudo as assevera, tornando-as globais e intensificando a luta de classes.

Para dominar o espaço o capital precisa produzi-lo, é necessário superar as barreiras que impedem sua livre circulação, mas é um processo que gera tensões. As estruturas locais são abaladas, mas não sem gerar conflitos, as horizontalidades não são hegemonizadas sem impor resistências, o local também pode ser o palco da obstinação, aproximando os sujeitos envolvidos.

Os atores desse processo não poderiam ser outros se não os trabalhadores, eles são a base da criação de infraestruturas que asseguram a livre circulação de capital, mas aqui entramos numa contradição:

As infraestruturas necessárias absorvem capital e força de trabalho na sua produção. Aqui, aproximamo-nos da essência do paradoxo. Parte da totalidade do capital e da força de trabalho tem de ser imobilizada no espaço, congelada no espaço, para proporcionar maior liberdade de movimento ao capital e à força de trabalho remanescentes. No entanto, o argumento, nesse momento, volta ao começo, pois a viabilidade do capital e do trabalho comprometidos com a produção e a manutenção de tais infraestruturas apenas fica assegurada se o capital remanescente circular por vias especiais e num período de tempo compatíveis com o padrão geográfico e a duração de tais compromissos. Se essa condição não for satisfeita [...] então o capital e o trabalho comprometidos ficarão sujeitos à desvalorização (HARVEY, 2005, p. 149150).

É nesse contraditório processo, inerente ao capitalismo, que temos o desenvolvimento das cidades. Há uma tendência nas últimas três décadas do século passado e, principalmente a partir da década de 1980, dos aglomerados urbanos adotarem práticas "empreendedoras", para atrair 
investimentos, substituindo as práticas estritamente "administrativas", cada vez mais em decadência. As políticas habitacionais do Estado ficaram cada vez mais esgotadas (HARVEY, 2005). Esse processo de reestruturação produtiva do capital trouxe grandes mudanças para o capital imobiliário, modificando drasticamente a relação com o espaço. 0 meio onde se realiza a vida também é o meio onde o capital se valoriza, o espaço se torna uma mercadoria que o capital se apropria, ou melhor, "expropria" como forma de se reproduzir:

Na contemporaneidade, a sociedade é dominada pelo econômico, de maneira que a acumulação se concretiza na produção de um espaço mundializado como tendência e momento de realização do capitalismo, apontando que a necessidade de superação dos momentos de crise se faz pela incorporação de novas produções ao processo de acumulação, dentre elas a do espaço urbano, que se efetiva com a hegemonia do capital financeiro (CARLOS, 2015, p.44).

Isso não quer dizer que o Estado deixa de ser instrumento regulador no processo de produção capitalista, pelo contrário, ele desempenha um processo fundamental na coordenação dos novos arranjos, afinal,

É dele o controle do fundo público para investimentos, e cabe a ele sob a forma de poder local, a regulamentação e o controle sobre o uso e a ocupação do solo (segundo, hipoteticamente, planos e leis aprovadas nos parlamentos). É, portanto, o principal intermediador na distribuição de lucros, juros, rendas e salários (direto e indireto), entre outros papéis. Há, portanto, uma luta surda pela apropriação dos fundos públicos, que é central para a reprodução da força de trabalho ou para a reprodução do capital (MARICATO, 2015, p. 25).

Segundo Volochko (2015), a crise financeira de 2008 remodela o mercado imobiliário no Brasil. Há uma tendência à saída dos investimentos financeiros no setor:

Nesse contexto turbulento de crise, muitas incorporadoras reavaliam suas parcerias e estratégias de mercado, optando por arriscar menos. Mas o grande motivo que leva as incorporadoras a levar adiante a periferização/metropolização da produção imobiliária da moradia foi o modo como o Estado propôs lidar com a crise no Brasil: privatizando a política urbana no dia 25/03/2009 com o lançamento do Programa MCMV [Minha Casa Minha Vida], que conta com intensa participação de grandes incorporadoras em todas as fases (VOLOCHKO, 2015, p. 113).

O Programa Minha Casa Minha Vida vem para atender uma demanda social que também é necessária à reprodução de mão de obra para o próprio capitalismo, isto é, a moradia. Mas, através da canalização de recursos públicos para o setor privado, o programa cumpre um papel importante na acumulação capitalista, se torna extremamente lucrativo para o capital ampliando ainda o fenômeno urbano de fragmentação da metrópole em áreas periféricas.

A moradia é uma das necessidades primordiais humanas, Marx e Engels (2005, p. 53) já colocavam esta como uma das necessidades primárias que os homens precisam suprir antes de atender a outras necessidades: "todos os homens devem estar em condições de viver para poder fazer história", diziam esses filósofos. Este pressuposto, apesar de todo o progresso da sociedade, é algo ainda inacessível para uma massa de milhões de pessoas. 0 sentido da moradia pode se alterar conforme a sociedade e o tempo, mas persiste: 
Num mundo do movimento, a realidade e a noção de residência (Husserl, Heidegger, Sartre) do homem não se esvaem. O homem mora talvez menos, ou mora muito menos tempo, mas ele mora: mesmo que ele seja desempregado ou migrante. A "residência", o lugar de trabalho, por mais breve que sejam, são quadros de vida que têm peso na produção do homem (SANTOS, 2014, p. 328, grifo do autor).

Friedrich Engels (2015) na sua polêmica com Arthur Mülberger sobre a questão da moradia na Alemanha, que vivenciava um impressionante desenvolvimento urbano, já conclamava a incapacidade do sistema capitalista em resolver o problema urbano e que só a revolução social poderia trazer uma solução. Com uma lucidez característica de seu grande rigor teórico-metodológico, Engels efetuou uma análise das cidades da época que em nada ficou desatualizada, outrossim, o leitor que não souber que está a ler um texto com quase 150 anos poderia enxergar claramente até a realidade brasileira nas palavras do autor:

A expansão das metrópoles modernas confere ao terreno situado em certas áreas, especialmente nas mais centrais, um valor artificial, que com frequência, aumenta de forma colossal; os prédios construídos nelas, em vez de elevar esse valor, acabam pressionando-o para baixo, porque não correspondem mais às novas condições; eles são demolidos e outros construídos em seu lugar. Isso acontece sobretudo com moradas de trabalhadores localizadas no centro, cujo aluguel, por mais superlotadas que estejam as casas, jamais ou só muito lentamente teria como ultrapassar um certo valor máximo. Elas são demolidas e, em seu lugar constrói-se lojas, depósitos de mercadorias, prédios públicos. [..] 0 resultado é que os trabalhadores são empurrados do centro das cidades para a periferia. (ENGELS, 2015, p. 39-40).

Essa é uma tendência geral que Lênin já destacava no início do século passado ao mostrar como o monopólio é inerente ao capitalismo. Em "Imperialismo, estágio superior do capitalismo", esse teórico revolucionário também se deteve à discussão da especulação imobiliária:

Uma das operações particularmente lucrativas do capital financeiro é também a especulação com terrenos situados nos subúrbios das grandes cidades que crescem rapidamente. 0 monopólio dos bancos funde-se nesse caso ao monopólio da renda da terra e com o monopólio das vias de comunicação, pois o aumento dos preços de terrenos, a possibilidade de vendê-los vantajosamente em parcelas, etc. dependem principalmente das boas vias de comunicação com a parte central da cidade (LÊNIN, 2012, p. 85-86).

Dentro do que já foi debatido, vê-se que é impossível entender o capitalismo sem entender o que é a cidade (e vice-versa), cuja principal representação é a grande metrópole. As metrópoles hoje são o grande palco da exclusão social causada pela mercantilização da vida; elas se configuram como o local da reprodução do capital no ciclo da produção de mercadorias e do capital financeiro.

A própria metrópole se configura como uma força produtiva (CARLOS, 2015), o espaço enquanto mercadoria traz implicações para todos os demais setores produtivos, pois, sua expansão garante a ampliação dos demais capitais. Uma nova área habitacional, por exemplo, não implicará apenas na movimentação do setor da construção civil; serão atraídos vários outros capitais que atendam a demanda de consumo da população, numa breve hipótese: o capital varejista, educacional, de segurança, etc. 
A cidade que nasce enquanto valor de uso para seus cidadãos passa a ter essa lógica modificada, isso é um grande símbolo da fetichização do espaço. Marx (2013) já esboçava em 0 Capital esse caráter trivial da mercadoria. Enquanto valor de uso não há nada de misterioso, mas ao assumirse como valor de troca, seu caráter místico surge; o trabalho social humano é coisificado na mercadoria que passa a existir como se isso fosse algo inerente a ela; não se é mais encarada como uma relação social entre pessoas, mas como uma relação social entre coisas. Esse problema da formamercadoria passa a ser imperativo a partir do momento que esta assume o caráter universal das trocas no capitalismo, diferentemente das sociedades pré-capitalistas, onde o valor de troca estava diretamente submetido ao valor de uso. Esse é um problema elementar do capitalismo, todas as relações sociais permeiam direta ou indiretamente essa lógica. A esse fenômeno, a essa forma de alienação própria do capitalismo, Lukácks, analisando o pensamento de Marx, chama de reificação:

Apenas nesse contexto a reificação surgida da relação mercantil adquire uma importância decisiva, tanto para o desenvolvimento objetivo da sociedade quanto para a atitude dos homens a seu respeito, para a submissão de sua consciência às formas nas quais essa reificação se exprime (LUKÁCS, 2003, p. 198).

Como explica Mészáros (2006), o conceito de alienação em Marx é historicamente construído, suas bases estão assentadas na materialidade, deste modo, não se perdem em explicações idealistas como fazem as demais correntes filosóficas e a teologia, podendo assim apresentar uma proposta concreta de superação dessa problemática.

Marx desenvolve sua teoria da alienação sob dois aspectos principais: o estranhamento do homem em relação a natureza de si mesmo, isto é, à sua própria atividade e; como consequência disso, o estranhamento do homem em sua relação com a natureza e com os outros homens. Por estar diretamente ligada à atividade fundamental humana, ou seja, o trabalho, todas as demais formas de alienação no capitalismo são consequência dessa forma geral de estranhamento no processo primário de produção do ser social.

Ao falarmos em habitação, o espaço que se trata não poderia ser outro senão o imobiliário e, como já discutido, não se separa o espaço real do espaço abstrato, isto é, os sentidos que cada comunidade atribui a sua forma de moradia. De que modo então se dá a alienação desse espaço utilizado para a residência? Uma breve reflexão na história nos ajuda a explorar dimensões desse questionamento.

A terra enquanto capital produtivo no feudalismo possuía uma dimensão própria de alienação: “A propriedade agrária feudal é considerada como uma manifestação particular da alienação, porque o fato de a terra ser possuída por uns poucos grandes senhores significa que o solo foi estranhado do homem em geral e se opõe a ele como um poder alheio" (MÉSZÁROS, 2006, p. 125); a ideologia feudal a coloca como inalienável ao homem e traz determinações metafísicas que a legitimam. Isso é modificado sob o julgo do capital, é preciso que o homem possa legitimamente negar 
a posse dessa terra para vários outros enquanto a toma privadamente para si. Aqui não é a força divina que dá a outorga, esse papel é cumprido pela "legalidade" jurídica constituída nos Estados modernos. A noção de "igualdade" (violentamente construída com as cabeças da monarquia francesa) é trazida para a sociedade para legitimar a desigualdade, é completamente desprovida de conteúdo, puramente posse de direitos. Direitos de quem? De quem tem as posses.

O espaço urbano obviamente não foge a lógica da mercadoria no capitalismo, integrando também as leis gerais da acumulação. Nesse processo, é o trabalho social humano quem produz o valor que se incorpora à terra:

Pensamos que a urbanização é também um processo de transformação da renda do solo em valor do solo, valor dos imóveis e valor do espaço urbano, dados pelo trabalho social e pela constituição de um mercado imobiliário urbano - um mercado de espaços edificados e de espaços com perspectiva de edificação ou de alguma transformação presente ou futura - que certamente especula com essa valorização do espaço para elevar os preços seja da terra, seja dos imóveis construídos ou em construção (VOLOCHKO, 2015, p. 101).

Deste modo, essa necessidade inerente a manutenção da vida humana (e da força de trabalho ao capital) passa a ser uma mercadoria extremamente lucrativa que também reproduz a lógica da estratificação social típica de um sistema de classes. Temos o espaço destinado a moradia dos trabalhadores e o destinado à moradia dos patrões.

Nesse processo de produção do espaço, o capital cria novas simbioses do urbano, há o que Lefebvre (2002) chama de "fetiche da natureza". A sociedade industrial a devastou, mas tenta reproduzi-la de alguma forma (num espaço verde, numa árvore, etc.) para suprir ilusoriamente essa necessidade de contato com o "livre" representando por ela. A realidade urbana tem em mente o rural, mas lida com o "cotidiano" industrial alienante, se encontra presa a ele. A cegueira (alienação) do urbano consiste em não ver a ampla forma que esta realidade representa, isto é, a forma de vida social emancipada ainda não conhecida, uma vez que é preciso superar o sistema de classes para tal.

Segue-se um erro, ou uma ilusão: colocar o espaço social fora de alcance, escamoteia seu caráter prático para gerar uma espécie de absoluto à maneira dos filósofos. De modo que o "usuário" faz espontaneamente abstração de si, de sua presença, de seu "vivido" e de seu corpo, face a esta abstração tornada fetiche. O espaço abstrato fetichizado engendra, ao mesmo tempo, essa abstração prática do "usuário" que não se percebe num tal espaço, e a abstração da reflexão, que não concebe a crítica (LEFEBVRE, 2006, p.139, grifos do autor).

O urbanismo também contribui para essa cegueira, é a tentativa de naturalizar o industrial, suprir o vazio deixado pela destruição da "natureza natural" e também da "natureza humana". Nesse processo, como teoriza Carlos (2015), o que se vende não é a cidade, mas o urbano dentro do que essa totalidade se constitui nas amarras do capitalismo. 


\section{A URBANIZAÇÃO DO AÇUDE DO DNOCS}

Muito há que se falar sobre o Lago da Perucaba. Este é considerado um dos cartões postais da cidade, mas hoje está abandonado. As academias ao ar livre, as barracas destinadas ao comércio, as quadras esportivas, parques para crianças, enfim, as obras como um todo na área encontram-se sem qualquer manutenção há alguns anos. Partindo dessa realidade, como cidadão, uma conclusão é óbvia e já convencional quando se trata de problemas com bens públicos: a responsabilidade por isso é do Estado, da atual gestão da Prefeitura de Arapiraca que está sendo negligente com o local. Mas se pegarmos essa visão de cidadão e acrescentarmos a ela o ponto de vista de um cientista social e historiador, há bem mais coisas que podemos enxergar nesse processo.

Primeiramente a "harmonia" da área não está sendo afetada pela degradação do patrimônio público, o atual estado de abandono é apenas uma consequência de outro processo econômico-social mais recente, que não será desenvolvido nesse artigo, mas ao qual faremos alguns apontamentos nas considerações finais. 0 que ocorre é que toda a obra em si mascara uma realidade marcada pelos interesses e conflitos entre classes sociais que, por se tratar de uma mudança recente, se tornam bastante explícitos à uma observação mais atenta.

Na parte sul do Lago, há uma comunidade de pescadores. São alguns barracos feitos de taipa e madeira onde residem os moradores e é guardado material para a pesca; ali também há canoas e gaiolas usadas como criatório para peixes. Bem próximo a essa simples comunidade, na margem sudoeste, um imponente empreendimento imobiliário produz um contraste nesse espaço. 0 Perucaba Bairro Planejado, primeiro bairro planejado de Alagoas como seus divulgadores fazem questão de anunciar33, na verdade está sendo construído em uma área não planejada, pois o Plano Diretor de Arapiraca (Lei 2424/2006) classifica as proximidades do açude como uma Zona Especial de Interesse Ambiental (ZEIA) destinada à proteção do patrimônio ambiental natural (uma clara evidência da sobreposição dos interesses econômicos particulares sobre o público). O Bairro Planejado consiste em dois empreendimentos: o Reserva Perucaba e o Jardins Perucaba, ambos de alto padrão, mas sendo o segundo mais "acessível”, cujas mensalidades dos lotes mais cômodas ultrapassam 600 reais, o que já delimita o estrato social que consegue acesso ao projeto ${ }^{4}$. Para entendermos melhor esse contexto, uma observação histórica ajudará bastante.

O atual Lago da Perucaba é uma obra de urbanização de um açude público de porte médio do Departamento Nacional de Obras Contra as Secas com capacidade para $4.130 .500 \mathrm{~m}^{3}$, cuja construção foi iniciada após a aprovação do projeto em 19625, sendo inaugurado em 19656. Sabe-se através de

\footnotetext{
3 Urbis Perucaba Empreendimentos (2019).

${ }^{4} \mathrm{Na}$ margem Norte do açude também encontramos um outro empreendimento de alto padrão nos moldes de um condomínio fechado que está inserido no mesmo contexto de especulação imobiliária, o Residencial Riviera do Lago.

5 Diário Oficial da União de 24/09/1962 (BRASIL, 1962).

${ }^{6}$ Câmara Municipal de Arapiraca (1965).
} 
depoimentos orais de antigos moradores da área7 que já existia um açude menor muito antigo, cuja construção é atribuída ainda aos últimos anos do século $\mathrm{XIX}^{8}$. A ampliação do açude se encaixa no contexto de ações do DNOCS no Polígono das Secas do Nordeste, planejadas desde a década de 1950. Não apenas em Arapiraca, mas em várias outras cidades do Nordeste, açudes como este foram inaugurados, sendo usados pelo regime ditatorial então instalado no Brasil como propaganda das ações realizadas pelo governo militar em seu primeiro ano, sempre estando presentes nas festividades várias autoridades locais e, entre elas, o ministro da Viação e Obras Públicas, mal. Juarez Távora99.

A principal proposta ao construir o açude era abastecer com água a comunidade de Arapiraca ${ }^{10}$, uma finalidade desde o início problemática, pois, as águas do Riacho Perucaba, represado para provocar a inundação, tem altos teores salinos, não sendo potável. Mas mesmo esse fator não parece ter sido razoável para os engenheiros, que chegaram a fazer a encanação para levar água do açude à praça do bairro de Cacimbas (um dos bairros mais populosos de Arapiraca, próximo cerca de $1 \mathrm{~km}$ do local), onde haveria chafarizes. Os próprios moradores já viam que era uma obra que não daria certo, como relatou um entrevistado: "Eles ia... dizendo que ia encanar, botaram inté na praça ali, aqueles cano dessa grossura, da rede d'água, dizem que ia botar pra rua. Água salgada rapaz! 'fica doce', doce aonde rapaz? As terra tudo salgada aí, no berço da Perucaba" (OLIVEIRA, 2019, np., grifo da transcrição). Podemos cruzar essa informação com a de um jornal da época, mostrando que foi uma situação até mais vexatória, pois foi preciso que o próprio ministro Juarez Távora mandasse suspender a ligação da água do Açude ao constatar que a mesma não servia para consumo humano:

Segundo nos informam de Arapiraca, o Ministro Juarez Távora, em sua recente visita áquela cidade, ao inaugurar o açúde de 4 milhões de metros cúbicos ali construído pelo DNOCS, teria determinado a suspensão imediata da obra de ligação do referido açúde a dois chafarizes para abastecimento da população local.

Na ocasião em que a obra era inaugurada, teriam chamado a atenção do ministro para o fato de que a cidade necessitava de água potável e não água salgada como a existente no açúde. Verificando que o líquido do reservatório realmente era de alto teor de salinidade, o titular da Viação e Obras Públicas prometeu o apoio do DNOCS, no sentido da construção duma adutora que abasteça Arapiraca com água do São Francisco.

Estaria assim o problema da "capital do fumo" para sempre solucionado em tôrmos definitivos através da Casal, a quem o DNOCS transferiria recursos destinados à construção duma adutora nos moldes da que já está sendo construida pela Cia. De Abastecimento dágua e Saneamento, na Bacia Leiteira do sertão alagoano (sic) (JORNAL DE ALAGOAS, 08/04/1965, p.6).

Nas memórias de um historiador local também encontramos um lamento quanto a realização dessa obra que extinguiu uma área utilizada para lazer onde a população se banhava, principalmente, durante as cheias do Perucaba: "construir uma barragem em um riacho de água insalubre, como a Perucaba, foi realmente um ato de pouco alcance, uma insensatez que, no futuro, iria dar trabalho

\footnotetext{
${ }^{7}$ Entrevistas orais realizadas reunidas em um acervo (LIMA, 2019).

8 Correia (1972).

${ }^{9}$ Imagens do Brasil (2010).

10 Ofício 136-T de 24/09/1962 do diretor Geral do DNOCS (PODER JUDICIÁRIO DE ALAGOAS, 2014, p. 215).
} 
novamente para desativar a água represada e completamente poluída com os esgotos de hospitais dejetos de matadouros, sujeira de mercado público, etc." (GUEDES, 1999, p. 131).

Na explicação a seguir encontramos um dos motivos que levaram obras como a do açude de Arapiraca a terem tão pouca serventia:

Os projetos de construção que existem para cada açude obedecem a um modelo comum, que se concentra quase que exclusivamente nos aspectos de engenharia da barragem, sem incorporar nenhuma avaliação rigorosamente econômica, dando apenas vagas indicações dos usos futuros para a água acumulada. Somente depois da construção, e num ritmo lento, projetos foram feitos, e ainda assim para uma minoria de casos, para explorar a irrigação de culturas, o cultivo das áreas de montante, a criação de peixes, a perenização de rios e o abastecimento de água de áreas urbanas e rurais (ASSUNÇÃO, LIVINGSTONE, 1993, p. 430).

De fato, além do orçamento de despesas, o relatório para a obra trata apenas de questões técnicas quanto ao emprego do solo na construção de barragem de terra ${ }^{11}$. Somente um ano após a construção do açude é realizado um estudo sobre as condições do solo e da água, sendo descartado tanto sua potabilidade quanto seu uso para irrigação, no máximo como irrigação complementar no verão, mas sendo recomendando pelo engenheiro um estudo prévio numa área piloto, já aconselhando também o cultivo de culturas tolerantes a sal, além de avaliar se os possíveis benefícios compensariam o investimento necessário para tal ${ }^{12}$.

Com a finalidade principal da construção frustrada, permaneceu o usufruto de antes da intervenção do DNOCS, ainda no velho açude: a pesca. Após a construção começou a se estabelecer às margens uma comunidade de pescadores que complementavam ou mesmo tiravam todo seu sustento dessa atividade, como os próprios relatam em entrevista, há inclusive pescadores que dizem ser filhos de trabalhadores da obra. Relatório do DNOCS confirma a afirmação sobre a ocupação antiga da área:

Situação do Açude: 0 açude Arapiraca está localizado em areas urbana e suburbana da cidade de mesmo nome, acumulando $4.700 .000 \mathrm{~m}^{3}$ d'água. Sua bacia de capitação é boa, fazendo que êle sangre de 5 a 6 meses por ano o que de certo modo é um benefício, pois evita que a sua água venha se tornar maiores concentrações de sal.

Sua linha de contôrno (faixa sêca) incluirá nada menos de 18 casas residenciais, além do matadouro da cidade localizado no fim da avenida norte. A região é essencialmente agrícola, predominando a cultura do fumo que é a base econômica; a Pluviosidade é em média $1.200 \mathrm{~mm}$ ano (sic) (BEZERRA, 1966, p. 210, grifo nosso).

Aqui vemos como essa área foi historicamente desvalorizada aos olhos do poder econômico. 0 Açude do DNOCS passou a ser o destino dos dejetos do matadouro público que já funcionava há anos no local e também dos esgotos do Centro da cidade e bairros vizinhos. A ocupação das proximidades foi se dando de forma irregular, mas não que essa seja a realidade apenas desse local da cidade, pois, o processo de expansão urbana e o mercado habitacional em si nunca seguiu uma organização planejada em Arapiraca (SANTOS, SANTOS, BARBOSA, 2015), mas esse é um dos pontos onde nota-se que foi povoado por pessoas de baixa renda, afinal, basta olhar o tamanho dos lotes à época da construção ou,

\footnotetext{
11 Relatório no 72-LS-1961 (Idem, p. 206).

12 Considerações sôbre solo e água do Açude Público Arapiraca-AL (Idem, p. 210).
} 
no presente, a morfologia da área ao caminhar pelas ruas e o perfil socioeconômico dos moradores, qualquer um desses fatores já é suficiente para essa conclusão.

A intensificação da ocupação das áreas ao redor do açude que hoje compõe partes dos bairros Manoel Teles, Cacimbas e Zélia Barbosa Rocha se deu a partir da década de 1980. Nesses locais são registrados mais de 900 novos lotes para construção de casas no período de 1980 a 198513, a dimensão com certeza é ainda maior quando levamos em conta os lotes clandestinos, pois os mais de 30 mil espaços de moradia não regulados, segundo estimativas da Prefeitura em 2013 (ARAPIRACA, 03/07/2013), evidenciam que o movimento de ocupação da região faz parte de um longo processo histórico ocorrido na cidade. A necessidade de moradia empurrou famílias para ocupar áreas de baixio, encostas de esgotos, enfim, bairros como o Manoel Teles em Arapiraca, são um retrato da triste imagem das periferias das cidades grandes e médias que sofrem com a falta de estrutura urbana.

Até o final de 1998 os esgotos ainda eram jogados diretamente na barragem, quando o canal foi desviado para contornar o local e findar mais a frente, já no leito do riacho Perucaba. É nesse momento que se inicia o projeto de urbanização da área, mas ainda lenta, cheia de entraves quanto a liberação de recursos federais e planos de recorrer até ao Banco Mundial14. Apesar do desvio direto dos esgotos, o matadouro público ainda permaneceu jogando diretamente seus rejeitos nas águas, ainda havendo o descarte de resíduos sólidos, assim a poluição continuou em altos níveis, de modo que em 2005 uma reportagem caracterizava o açude como uma lagoa de esgotos ${ }^{15}$.

Esse histórico nos revela bem como essa era uma área segregada da cidade, ocupada por pessoas simples e com uma escassez enorme de serviços públicos. Mas isso começa a mudar a partir de 2007, quando finalmente são iniciadas as obras para urbanizar o açude, nesse momento ainda com o plano de construir 100 moradias populares em suas margens para os moradores (ARAPIRACA, 26/03/2007), o que não se concretizou. A prefeitura realizou uma desapropriação das casas situadas nas margens do açude, indenizando algumas famílias, mas não executou o projeto de moradias populares na área. Para aquelas pessoas, a normatização contida no Plano Diretor prevaleceu, não permitindo o estabelecimento de novas moradias em uma área de proteção ambiental, sendo a maioria destinadas a conjuntos habitacionais ${ }^{16}$, algo que, como vimos, não se aplicou para o Bairro Planejado. Aos olhos de grupos econômicos o resultado das intervenções tornou a área valorizada de mais para abrigar trabalhadores e grupos expropriados. É depois desse conjunto de melhorias que alguns moradores deixaram a margem leste do açude que passaria pela intervenção urbana e estabeleceram a atual vila em local que naquele momento não seria alcançado pela primeira fase das obras.

\footnotetext{
${ }^{13}$ Registro dos loteamentos construídos em Arapiraca de 1960 a 2015 fornecidos pela SEDUH (ARAPIRACA, 2015).

14 New Dinamic, 16/04/1999.

15 Gonçalves (2005).

16 Informação obtida através de um acervo de entrevistas de moradores da área (LIMA, 2019).
} 
Com a inauguração da primeira etapa de urbanização do agora denominado Lago da Perucaba em 200917, o empresariado local que já havia adquirido boa parte das terras da margem oeste do açude, enquanto ainda eram desvalorizadas, não perdeu tempo em lançar-se a empreitada imobiliária. 0 contexto nacional ajudou bastante, afinal era o período de lançamento do programa Minha Casa Minha Vida; as obras públicas da cidade também se inserem na conjuntura nacional pela qual o país passava no segundo Governo Lula, de oxigenação do setor privado com investimentos públicos, principalmente através do Programa de Aceleração do Crescimento (PAC):

\begin{abstract}
Em linhas gerais, conclui-se que as obras nos setores da infraestrutura previstas no PAC têm por finalidade principal reduzir os custos e acelerar o processo de circulação das mercadorias controladas por grandes empresas residentes no país, ou seja, atende a exigência dos grandes empresários que estão em busca de circular suas mercadorias de forma mais competitiva. E aprofunda o neoliberalismo, isto porque transfere ao capital privado a possibilidade de comercializar serviços básicos da sociedade, tais como: saneamento, habitação, transportes (estradas, metrô) etc. (SILVA, s.n.t., p.4).
\end{abstract}

Após a inauguração, o Lago da Perucaba foi por vários anos o centro de grandes eventos artísticos organizados pela prefeitura, a intenção realmente era consolidar a área como o point do lazer e do entretenimento da cidade. No final de 2013 o Bairro Planejado passou a ser destaque na imprensa local, fazendo uma grande campanha de marketing. Em uma destas reportagens podemos enxergar bem, além da lógica econômica, a narrativa social do empreendimento: “O empresário prevê que Arapiraca deve crescer, na próxima década, o dobro do que foi desenvolvido nos últimos dez anos. Por todo esse cenário, ele afirma que 'é um privilégio morar hoje em Arapiraca”". (SETE SEGUNDOS, 06/11/2013, np.). 0 grifo trazido na própria reportagem é o ponto onde queremos chegar. Quando observamos o contexto político do espaço podemos compreender que o sentido de "privilégio" trazido na reportagem tem sérias implicações sociais.

Apesar dessas realizações, dois fatores após a urbanização do açude ainda continuaram sendo um estorvo para o Bairro Planejado. Um deles já foi "resolvido", pois tratava-se do matadouro público que funcionava as margens do açude. Por mais de meio século a "matança", como era popularmente conhecido, funcionou no local sendo responsável pelo abate de animais de corte não só de Arapiraca, mas da região. A cidade cresceu, centenas de moradores passaram a residir nas suas proximidades e a sofrer os estorvos diários que uma instalação como essa consequentemente traz, isto é, mau cheiro, moscas etc. Desde 1999 que se fala, ou melhor, que existe o projeto de retirar o matadouro do local ${ }^{18}$, porque reclamações sobre esses problemas sempre existiram, mas só foi efetivada no início de 2016, processo que também carrega interesses e conflitos entre os pequenos comerciantes de carne, os marchantes, e a FrigoVale, concessionária privada que ganhou a licitação para administrar o novo matadouro público. Durante anos não houve pressa do poder público em executar a obra, mesmo após a finalização da primeira parte da urbanização do Lago, ocorrida em

\footnotetext{
17 Arapiraca, 20/03/2009.

18 New Dinamic, idem.
} 
2009. Tiramos essa conclusão do fato de as obras do novo frigorífico localizado na Zona Industrial da cidade só terem começado em $2010^{19}$ e estando cheia de problemas; inclusive nunca entrou em funcionamento mesmo após a inauguração em $2012^{20}$, pois já estava precisando de reformas ${ }^{21}$. Coincidentemente a agilização do processo de desativação do matadouro velho se deu após o lançamento do Bairro Planejado, afinal, além de estar na entrada do acesso ao condomínio, o mau cheiro era levado diretamente pelo vento ao local. Mas na verdade a aparente resolução desse problema apenas o transferiu para outro lugar onde os mesmos transtornos de antes poderiam agora afetar outras pessoas que não os moradores do novo empreendimento de luxo. Atualmente, o local do novo frigorífico se encontra no final do Distrito Industrial, já próximo ao maior conjunto habitacional de Arapiraca, o Brisa do Lago, cujos moradores não demoraram a sentir os efeitos ${ }^{22}$.

0 segundo fator ainda resiste nos dias de hoje. A comunidade de pescadores estabelecida próximo aos portões do empreendimento é uma continuidade histórica resistente a mudança sofrida por aquele espaço. É possível analisar como a Prefeitura atende claramente aos interesses do capital imobiliário quando a mesma move em 2014 um processo pedindo a reintegração de posse da área do Açude (cuja propriedade oficialmente é do DNOCS) alegando que pescadores que residem na área há mais de meio século a estariam "monopolizando". Como podemos ver nos argumentos utilizados pela procuradoria municipal:

O que pode parecer algo inofensivo está se tornando um enorme problema para o Município de Arapiraca. A área é importante para o Município, pois se trata de um bem de uso comum do povo e também área de preservação permanente. A importância da área para o Município e para sua população é tamanha que existe um grande projeto, cujo objetivo é a execução de obras, serviço de urbanização e infraestrutura nas áreas degradadas da margem e do entorno do Lago da Perucaba. Esse projeto imenso, que conta com repasses de verbas federais, já se encontra em sua segunda etapa e foi justamente nessa fase que a obra estagnou, pois esbarrou na tal estrutura montada irregularmente pelos pescadores (PODER JUDICIÁRIO DE ALAGOAS, 2014, p. 5).

Se o peso usado para imputar aos pescadores o desacordo com normas ambientais fosse realmente isonômico, nunca deveria ter sido autorizada a construção do condomínio que, como dito, está situado em uma ZEIA. Nesses casos, uma máxima de Marx é mais do que correta para explicar o que ocorre: "Entre direitos iguais, quem decide é a força" (MARX, 2013, p. 309), assim o poder econômico mostrou ter a força maior. Santos et al. (2016), observam que a cidade "legal" está prospectada muito diferentemente da cidade "real":

Em Arapiraca, assim como outras cidades interioranas de porte médio, nota-se que a expansão urbana descontínua do tecido consolidado da cidade, com a existência de diversos vazios urbanos, tem apontado um fator de grande relevância para que um estudo mais aprofundado venha ser desenvolvido. Nesse contexto, a atuação do mercado imobiliário tenta se beneficiar de uma parcela da cidade, desrespeitando leis

\footnotetext{
${ }^{19}$ Arapiraca, $12 / 03 / 2010$.

${ }^{20}$ Arapiraca, 29/10/2012.

${ }^{21}$ Arapiraca, 09/01/2013.

22 Costa (2018).
} 
de instrumentos norteadores de expansão e de desenvolvimento urbano (SANTOS et. al., 2016, p. 11-12).

Não se duvida também que a área é importante para o município, como afirmado pela Procuradoria, afinal se levarmos em conta a quantidade de convênios firmados entre Arapiraca e o Ministério do Turismo nota-se que em sua maioria são para intervenções nesse local: de oito convênios, entre 2008 e 2016, seis estão voltados a obras que abrangem a área do Lago da Perucaba ${ }^{23}$ (BRASIL, 2017); o que nos cabe questionar é para que ou quem essa área é importante? Para quem sempre morou lá? Para os turistas de fora? Para a nova classe média e alta que residirá no local?

Respostas para essas perguntas são tiradas de mais alguns fatos presentes nesse contexto de especulação imobiliária. Ao mesmo tempo em que essa ação é movida, o empreendimento Perucaba Bairro Planejado já divulga em seus folders de propaganda um projeto de construir um hotel de luxo exatamente no local onde se localiza a vila dos pescadores, como mostra a Figura 01.

Figura 01. Imagem ilustrativa do Perucaba Bairro Planejado. Destaque em círculo da área em questão.

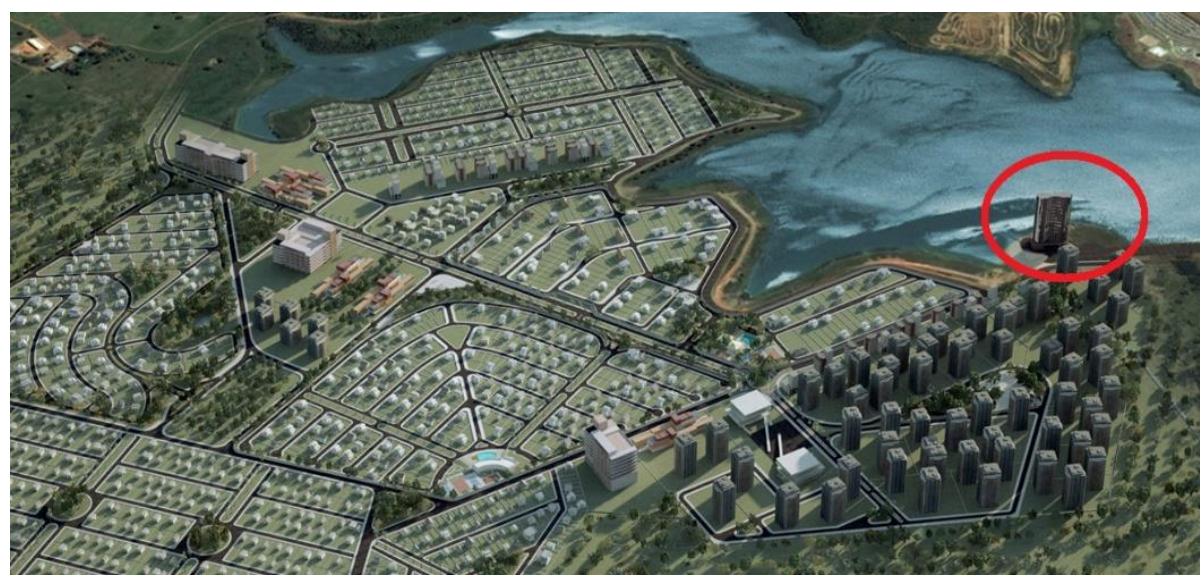

Fonte: Urbis Perucaba Empreendimentos (2019).

Isso nos levou a tentar entender um pouco mais acerca da relação do empresariado local com as gestões da prefeitura. Isso é um fato que achamos prudente considerar, uma vez que:

Os processos de mudança são, com frequência, fenômenos de poder, na evolução das sociedades. E o controle da mudança, por sua vez, quase sempre aparece como fenômeno político (ele não diz respeito, somente, ao poder em geral, como poder econômico, social ou cultural, indiretamente político; mas, também, ao poder especificamente político) (FERNANDES, 2013, p. 54).

Destarte, optou-se por analisar as doações de campanha das eleições municipais. Para este trabalho, consultando as contas eleitorais das eleições de 2012, cujos documentos possuem uma acessibilidade mais fácil por estarem disponíveis na internet, identifica-se através da análise das planilhas de doadores, que os empresários (pessoa física) e grupos empresariais (pessoa jurídica) que

\footnotetext{
${ }^{23}$ Refere-se aqui a convênios cuja liberação de recursos se concretizaram. Há vários outros planos de cooperação com outras entidades e órgãos da União, mas esses já são suficiente para demonstrar o foco principal nesta área.
} 
são direta ou indiretamente ligados ao empreendimento Perucaba Bairro Planejado foram responsáveis por cerca de $1 / 4$ das doações para a campanha da candidata vitoriosa no pleito (TSE, 2012a). Curiosamente o candidato que ficou em segundo lugar na disputa, também recebeu do mesmo grupo empresarial, excetuando os recursos advindos das pessoas físicas dos empresários, uma doação de mesmo valor (TSE, 2012b). Esses dados nos servem de apoio para uma hipótese bem evidente: não se tratam de "doações", mas de "investimentos" dos quais se espera um retorno e, dentro dessa lógica, a figura do político que esteja no poder não é o ponto mais significativo, já que há apostas nos dois lados.

\section{CONSIDERAÇÕES FINAIS}

Este é um pouco do contexto socio-histórico presente no espaço em análise. 0 aporte teórico discutido na primeira parte deste artigo nos ajuda bastante a entender o fenômeno urbano arapiraquense. A partir do entendimento do espaço como sendo formado por sistema de objetos e sistema de ações, podemos analisar como se dá a reprodução da vida humana que obviamente não é homogênea e a melhor forma para encontrar as distinções se dá através dos interesses das classes sociais existentes. Os mais humildes têm a sua forma própria de utilizar o espaço ao longo do tempo, e do mesmo modo as elites têm o seu projeto particular. É uma forma didática de entender a ação das horizontalidades e verticalidades, conceitos também trazidos por Milton Santos. O poder econômico se manifesta como um vetor perturbador, mas encontra formas próprias de resistência onde quer que conflitue com as forças horizontais.

Se entendêssemos este espaço como fragmentado, isto é, enxergando o Lago da Perucaba apenas como um espaço de lazer, teríamos uma visão limitada do todo. A área faz parte de uma totalidade maior, não é só o espaço do lazer, é o espaço do morar, do trabalhar, do intercâmbio, também um espaço do simbolismo, enfim, são vários elementos imbricados uns sobre os outros que precisam ser abstraídos:

A abstração é a capacidade intelectiva que permite extrair de sua contextualidade determinada (de uma totalidade), um elemento, isolá-lo, examiná-lo; é um procedimento intelectual sem o qual a análise é inviável[...]. A abstração, possibilitando a análise, retira do elemento abstraído as suas determinações mais concretas, até atingir "determinações mais simples" (NETTO, 2011, p. 44).

Se, como vimos, toda a realidade de um espaço tem sua gênese no "tempo", é preciso dar uma atenção especial a essa categoria, e com ela é a História quem tem propriedade para lidar. Para Braudel (1965), no seio das ciências sociais, uma das contribuições que a história tem a trazer é a compreensão das multitemporalidades que não dizem respeito apenas ao passado, mas também à sociedade atual. Nesse sentido, uma visão focada num momento muito curto pode prejudicar a ótica do 
historiador por esse contexto carregar elementos de um período anterior. Assim, o prolongamento no tempo se tornou necessário para enxergar os elementos de permanência no espaço. A partir disso, também podemos ter uma visão mais precisa da velocidade dos processos históricos. Podemos acompanhar como a cada ano, a cada década, mais e mais rápido ocorre a transformação do espaço, o Mundo se "mundializa" e Arapiraca está nesse Mundo, não foge as lógicas mais englobantes.

A ideologia do crescimento está impregnada no processo de urbanização aqui discutido, afinal, todas essas intervenções não vem desacompanhadas do devido discurso ideológico necessários para legitimar as ações do poder público, que como vimos, segue os ditames do poder econômico. No seio desses conflitos está a transformação do espaço em mercadoria, onde o valor de troca impera cada vez mais sobre o valor de uso. Com um pouco mais de atenção, podemos encontrar as contradições que permeia todos os processos sociais, em todas as esferas. É daí que podemos entender que o atual abandono do Lago da Perucaba está ligado a recente crise político-econômica que todo o país passa e até mesmo a mudança de grupo político à frente do executivo municipal, mas este é um debate para outro momento.

Acredita-se que as considerações aqui discorridas contribuíram para avançar na compreensão do estudo dos fenômenos urbanos partindo de um enfoque materialista, e pode trazer ainda uma contribuição científica importante para a historiografia sobre Arapiraca, entendendo a conjuntura urbana da cidade enquanto um processo histórico. As forças econômicas vêm ditando os rumos da cidade, mas existem resistências que precisam ser enxergadas e compreendidas, muitas questões ainda merecem ser indagadas que também devido aos limites deste trabalho, não podem ser aqui discutidas, como, por exemplo, por que, dentre vários processos de desapropriação em Arapiraca, uma pequena comunidade de pescadores oferece uma persistente resistência quando ocupações bem maiores não ofereceram? Algo a ver com a organização de um movimento social pelos pescadores ou com o aporte jurídico estabelecido? São questões que ainda vão ser aprofundadas. Algo necessário para dar visibilidade a essas lutas como meio de fortalecê-las, fomentando assim alternativas que possam beneficiar a população prejudicada pela forma como a cidade vem crescendo.

\section{REFERÊNCIAS}

ANDRADE, M. C. de. A terra e o homem no Nordeste: contribuição ao estudo da questão agrária no Nordeste. 8ª ed. São Paulo: Cortez, 2011.

ARAPIRACA. Arapiraca recebe outro belo cartãopostal. Prefeitura de Arapiraca - Site Oficial. Arapiraca, 12/03/2010. Disponível em: <web.arapiraca.al.gov.br/2012/10/arapiracarecebe-outro-belo-cartao-postal/>. Acesso em: 28/03/2019.

. Arapiraca tem 30 mil imóveis clandestinos.

Prefeitura de Arapiraca - Site Oficial. Arapiraca,
03/07/2013. Disponível em:

<http://web.arapiraca.al.gov.br/2013/07/arapira ca-tem-30-mil-imoveis-clandestinos/>. Acesso em 27/03/2019.

. Arapiraca terá moderno matadouro público. Prefeitura de Arapiraca - Site Oficial. Arapiraca, 12/03/2010. Disponível em: < web.arapiraca.al.gov.br/2010/03/arapiraca-teramoderno-matadouro-publico/>. Acesso em: 28/03/2019. 
Estação de tratamento do matadouro público recebe melhorias. Prefeitura de Arapiraca - Site Oficial. Arapiraca, 09/01/2013. Disponível em: < web.arapiraca.al.gov.br/2013/01/estacao-detratamento-do-matadouro-publico-recebemelhorias/>. Acesso em 29/03/2019.

Feiras Livre de Arapiraca. Prefeitura de Arapiraca - Site Oficial. [S.n.t.]. Disponível em: < http://web.arapiraca.al.gov.br/servicos/feiralivre/ >. Acesso em 27/03/2019.

. Dep. Imprensa. Governo Luciano executa 12 obras em Arapiraca. Prefeitura de Arapiraca - Site Oficial. Arapiraca, 26/03/2007. Disponível em: <http://www.arapiraca.al.gov.br/v3_ok/noticia.p hp? notid=49>. Acesso em 04/06/2016.

Dep. Imprensa. Luciano e Renan garantem mais $R \$ 3$ mi para o Lago da Perucaba. Prefeitura de Arapiraca - Site Oficial. Arapiraca, 20/03/2009. Disponível em: < http://www.arapiraca.al.gov.br/v3/news_html.ph p?notid=1336 > . Acesso em 15/10/2015.

. Lei $n^{\circ} 2424$ de 23 de janeiro de 2006. Institui o Plano Diretor Participativo do Município de Arapiraca. Arapiraca: Centro Administrativo, 2006.

. Secretaria de Desenvolvimento Urbano e Habitação de Arapiraca - SEDUH. Loteamentos por data. [S. l.: s. n.], 2015. (Dados enviados por email).

ASSUNÇÃO, L. M.; LIVINGSTONE, I.

Desenvolvimento inadequado: construção de açudes e secas no sertão do Nordeste. Revista Brasileira de Economia, Rio de Janeiro, v. 47, n. 3, 1993. P. 425-448.

BEZERRA, G. E. Considerações sobre solo e água do Açude Público Arapiraca - AL. Ministério da Viação e Obras Públicas, Departamento Nacional de Obras Contra as Sêcas, $3^{\circ}$ Distrito de Fomento e Produção, Diretoria de Fomento e Produção, Divisão Agro-indistrual, 1966. In: PODER JUDICIÁRIO DE ALAGOAS. 4⿳亠丷厂 Vara Civil de Arapiraca. Reintegração / Manutenção de Posse, processo número 0000992-62.2014.8.02.0058, Município de Arapiraca versus Omoacir Fernande da Silva e outros, P. 210. 15/02/2014.

BRASIL. Ministério da Transparência e Controladoria-Geral da União. Portal da Transparência. Convênios por órgão concedente: Ministério do Turismo e Município de Arapiraca. Disponível em:

<http://www.portaltransparencia.gov.br/conveni os>. Acesso em 26/10/2017.

. Ministério da Viação e Obras Públicas.

Portarias de 26 de outubro de 1962. Atendendo ao que propôs o DNOCS no Ofício 136-T de 24 de setembro de 1962. Diário Oficial, Brasília, DF, 06 de novembro de 1962. P. 11525.
BRAUDEL, F. História e ciências sociais: a longa duração. Tradução: Ana Maria de Almeida Camargo. Revista de História, vol. 30, n. 62, p. 261294, abr./jun. 1965.

CÂMARA MUNICIPAL DE ARAPIRACA. Ata da sessão de 03/04/1965. Arapiraca: Livro de Atas, 1965.

CARLOS, A. F. A. A tragédia urbana. In: CARLOS, A. F. A.; VOLOCHKO, D.; PINTO, I. A. (Orgs.). A cidade como negócio. São Paulo: Contexto, 2015. P. 43 63.

CORREIA, N. R. De Manoel André a Esperidião Rodrigues ou Roteiro Histórico dos Primórdios de Arapiraca. Fôlha de Arapiraca - o jornal do agreste, Arapiraca, 29 de out - 04 de nov de 1972. Segundo caderno.

COSTA, F. Moradores do Residencial Brisa do Lago reclamam do mau cheiro oriundo das atividades da FrigoVale. Já É Notícia, Arapiraca, 10/05/2018.

ENGELS, F. Sobre a questão da moradia. São Paulo: Boitempo, 2015.

FERNANDES, F. Mudanças sociais no Brasil: aspectos do desenvolvimento da sociedade brasileira. $1^{\underline{a}}$ edição digital. São Paulo: Global Editora, 2013.

FIRMINO, P. C. S. Arapiraca/AL e Itabaiana/SE: a feira livre como gênese e desenvolvimento de dois centros regionais do interior do Nordeste brasileiro. 2016. 316fls. Dissertação (Mestrado). Faculdade de Filosofia, Letras e Ciências Humanas da Universidade de São Paulo. Departamento de Geografia, São Paulo, 2016.

GONÇALVES, R. Açude se tornou lagoa de esgoto. Alagoas em Tempo, Arapiraca, 03 a 10/04/2005.

GUEDES, Z. (José Gomes Pereira). Arapiraca através do Tempo. Maceió: Gráfica Mastergraphy Ltda, 1999.

HARVEY, D. A produção capitalista do espaço. São Paulo: Annablume, 2005.

IMAGENS do Brasil: cinejornal informativo n.8. Produção: Agência Nacional, Brasília, 1965. Arquivo Nacional: 2010. Disponível em: <http://www.zappiens.br/portal/VisualizarVideo. do?_InstanceIdentifier $=0$ \&_EntityIdentifier $=$ cgiRiR GOg9hq6X79WSg7ACmJ01lrb3F09uMRUBz5DPXqI.\&idRepositorio=0 $>$. Acesso em:16/03/2019 IBGE - INSTITUTO BRASILEIRO DE GEOGRAFIA E ESTATÍSTICA. $O$ Brasil em Síntese. Produto Interno Bruto dos Municípios. AL/Arapiraca. [S.l].: IBGE, 2016. Disponível em: https://cidades.ibge.gov.br/brasil/al/arapiraca/p esquisa/38/46996>. Acesso em 16/03/2019.

O Brasil em Síntese. AL/Arapiraca. [S.l.]: IBGE, 2018. Disponível em:

<https://cidades.ibge.gov.br/brasil/al/arapiraca/ panorama >. Acesso em 16/03/2019.

JORNAL DE ALAGOAS. Juarez quer água do São Francisco para Arapiraca. Jornal de Alagoas. Maceió, 08/04/1965, p. 06. 
LEFEBVRE, H. A produção do espaço. Tradução: Doralice Barros Pereira e Sergio Martins. [S.l.: s.n.], 2006.

A revolução urbana. Belo Horizonte: Ed. UFMG, 2002.

LÊNIN, V. I. Imperialismo, estágio superior do capitalismo. São Paulo: Expressão Popular 2012

LIMA, E. D. A feira-livre na mediação campo-cidade. 2012. 185 fls. Dissertação (Mestrado). Núcleo de Pós-Graduação em Geografia. Universidade Federal de Sergipe, São Cristóvão, 2012.

LIMA, R. J. O. Acervo de entrevistas orais sobre o desenvolvimento de Arapiraca. Arapiraca: [s.n.], 2019.

LUKÁCS, G. História e consciência de classe: estudos sobre a dialética marxista. São Paulo: Martins Fontes, 2003.

MARICATO, E. Para Entender a Crise Urbana. São Paulo: Expressão Popular: 2015.

MARX, K. O capital: crítica da economia política: Livro I: o processo de produção do capital. São Paulo: Boitempo, 2013. (Marx-Engels).

MARX, K; ENGELS, F. A ideologia alemã: Feuerbach a contraposição entre as cosmovisões materialista e idealista. Tradução: Frank Müller. São Paulo: Martin Claret, 2005. (Coleção a obra-prima de cada autor).

MÉSZÁROS, I. A teoria da alienação em Marx. São Paulo: Boitempo, 2006

NARDI, J. B. Acabou-se o fumo: formação socioeconômica e espacial em Arapiraca-AL. Maceió: Q Gráfica, 2010.

NETTO, J. P. Introdução ao estudo do método em Marx. 1a ed. São Paulo: Expressão Popular, 2011.

NEW DINAMIC. Arapiraca espera verba para urbanizar açude. New Dinamic. Arapiraca, 16/04/1999.

OLIVEIRA, A. P. Entrevista 05. In: LIMA, R. J. 0. Acervo de entrevistas orais sobre o desenvolvimento de Arapiraca. Arapiraca: [s.n.], 2019.

PODER JUDICIÁRIO DE ALAGOAS. 4⿳亠丷a Vara Civil de Arapiraca. Reintegração / Manutenção de Posse, processo número 0000992-62.2014.8.02.0058, Município de Arapiraca versus Omoacir Fernande da Silva e outros. 15/02/2014.

SANTOS, C. S. Do luar do negócio à cidade como negócio. In: CARLOS, A. F. A.; VOLOCHKO, D.; PINTO, I. A. (Orgs.). A cidade como negócio. São Paulo: Contexto, 2015. P. 13 - 41.

SANTOS, J. C. et al. Estudo da evolução da malha urbana de Arapiraca-AL, Brasil: um comparativo entre a cartografia do plano diretor e os mapas georreferenciados contemporâneos. In: Congresso Luso Brasileiro para o Planejamento Urbano, Regional Integrado e Sustentável: Pluris: Contrastes, Contradições, Complexidades: Desafios Urbanos no Século XXI, 7, 2016. Maceió. Anais... Maceió: Viva Editora, 2016. P. 1 - 12.
SANTOS, J. C. dos; SANTOS, J. C. dos; BARBOSA, R. V. R. Análise têmporo-espacial do parcelamento de solo em Arapiraca utilizando Sistemas de Informação Geográfica (SIG). GEOALAGOAS Simpósio sobre geotcnologias e geoinformação do Estado de Alagoas, 3., 2015, Maceió. Anais... Maceió: SEPLAG, 2015. P. 66 - 73.

SANTOS, M. A natureza do espaço: técnica e tempo, razão e emoção. São Paulo: EdUSP, 2014. . A urbanização Brasileira. São Paulo: HUCITEC, 1993.

Técnica, espaço, tempo: globalização e meio técnico-científico-informacional. São Paulo: EdUSP, 2013.

SETE SEGUNDOS. Empreendimento imobiliário deve transformar setor em Arapiraca. Sete Segundos. Arapiraca, 06/11/2013. Arapiraca. Disponível em: <https://arapiraca.7segundos.com.br/noticias/20 13/11/06/26747/empreendimento-imobiliariodeve-transformar-setor-em-arapiraca.html $>$. Acesso em: 05/11/2017.

SILVA, C. O PAC do governo Lula e o processo de dependência e exploração da economia brasileira. [S.n.t.]. Disponível em: <http://www.sinasefe.org.br/antigo/Texto\%20so bre\%20o\%20PAC.pdf>. Acesso em: 28/03/2019.

TSE - TRIBUNAL SUPERIOR ELEITORAL. Sistema de Prestação de Contas Eleitorais - SPCE Web. Prestação de contas eleitorais. Consulta aos doadores e fornecedores de campanha de Candidatos. № Controle: 0001427057AL2871120. Data da entrega: 05/11/2012a

. Sistema de Prestação de Contas Eleitorais SPCE Web. Prestação de contas eleitorais. Consulta aos doadores e fornecedores de campanha de Candidatos. № Controle: 0004527057AL0293662. Data da entrega: 29/11/2012b.

URBIS PERUCABA EMPREENDIMENTOS. Perucaba, o bairro que já é uma realidade. [S.l.: s.n.], 2019. Disponível em: <http://perucababairroplanejado.com.br/>. Acesso em 27/03/2019.

VOLOCHKO, D. A moradia como negócio e a valorização do espaço urbano metropolitano. In: CARLOS, A. F. A.; VOLOCHKO, D.; PINTO, I. A. (Orgs.). A cidade como negócio. São Paulo: Contexto, 2015. P. 97 - 120. 